\title{
Seasonal and diel patterns in sedimentary flux of krill fecal pellets recorded by an echo sounder
}

\author{
Anders Røstad,1,2,* and Stein Kaartvedt 1,2 \\ ${ }^{1}$ King Abdullah University of Science and Technology, Red Sea Research Center, Thuwal, Saudi Arabia \\ ${ }^{2}$ Department of Biosciences, University of Oslo, Oslo, Norway
}

\begin{abstract}
We used a moored upward-facing $200 \mathrm{kHz}$ echo sounder to address sedimentation of fecal pellets (FPs) from dielly migrating Meganyctiphanes norvegica. The echo sounder was located on the bottom at $150 \mathrm{~m}$ depth in the Oslofjord, Norway, and was cabled to shore for continuous measurements during winter and spring. Records of sinking pellets were for the first time observed with an echo sounder. Seasonal patterns of sedimentation of krill FPs were strongly correlated with data from continuous measurement of fluorescence, which illustrate the development of the spring bloom. Sedimenting particles were first observed as fluorescence values started to increase at the end of February and continued to increase until the bloom suddenly culminated at the end of March. This collapse of the bloom was detected on the echo sounder as a pulse of slowly sinking acoustic targets over a $2 \mathrm{~d}$ period. Prior to this event, there was a strong diel pattern in sedimentation, which correlated, with some time lag, with the diel migration of krill foraging at night near the surface. Pellet average sinking speeds ranged between $423 \mathrm{~m} \mathrm{~d}^{-1}$ and $804 \mathrm{~m} \mathrm{~d}^{-1}$, with a strong relation to pellet target strength, which is an acoustic proxy for size. This novel approach shows that echo sounders may be a valuable tool in studies of vertical pellet flux and, thereby, carbon flux, providing temporal resolution and direct observation of the sedimentation process, which are not obtained from standard methods.
\end{abstract}

Sedimentary flux of fecal pellets (FPs) and of aggregates of phytoplankton from algal blooms is a key component of the biological pump that transports and recycles materials in the sea and is thereby important in transport of carbon from the atmosphere down to the deep ocean reservoirs (Wassmann 1997; Turner 2002). The extent and speed of this flux is therefore crucial for climate models estimating global warming (Honjo et al. 2008). The relative importance of sinking FPs in the vertical flux is varying and debated; the general view is that sedimentation of aggregated phytoplankton, often related to blooms, dominates the flux (Turner 2002), but FPs can become dominant with zooplankton assemblages in which large forms are abundant (Wexels Riser et al. 2010).

Mainly large FPs from macrozooplankton, such as krill (Wexels Riser et al. 2010), and feces from fish (Saba and Steinberg 2012) are involved in the sedimentary flux, whereas smaller FPs of smaller animals to a large extent are recycled in the water column (Turner 2002). Wexels Riser et al. (2010), addressing the role of zooplankton on vertical export of organic matter in a Norwegian fjord, found that the zooplankton community greatly influenced the vertical flux of particulate organic carbon through production and sinking of FPs. Krill were the single most important contributor to the vertical FP flux and made up $90 \%$ of the FP carbon during certain periods. FPs produced by numerically prevailing copepods played a minor role for the vertical flux, likely due to significant retention of the smaller FPs in the upper layers.

Patterns of sedimentation are normally studied by the use of sediment traps (Honjo et al. 2008). There are several

\footnotetext{
* Corresponding author: anders.rostad@kaust.edu.sa
}

studies of sinking rates of FPs of krill, measuring the sinking speed in containers in the lab (Fowler and Small 1972; Yoon et al. 2001; Atkinson 2012) or visually by divers or submersibles (Alldredge et al. 1987; Youngbluth et al. 1989). We here use an echo sounder to measure the temporal occurrence and sinking speed of FPs from krill (Meganyctiphanes norvegica) grazing on a phytoplankton spring bloom in a Norwegian fjord. We address seasonal variation in pellet production in relation to succession of the bloom and diel variations related to krill vertical feeding migrations. This was made possible by deploying a stationary, high-frequency echo sounder that was cabled to shore for continuous measurements. The echo sounder was located in a fjord with hypoxic bottom waters containing few other elements that reflect sound at depth, thereby facilitating detection of the weak pellet targets. This promising new method to measure vertical carbon flux provided unprecedented temporal resolution of pellet production and quantitative measurements of FP sinking speed in situ.

\section{Methods}

The studies took place in the $150 \mathrm{~m}$ deep Bunnefjorden, the inner branch of the Oslofjord (see fig.1 in Klevjer and Kaartvedt 2011). This is a very sheltered location, the deep waters have long residence time, and hypoxic and even anoxic waters commonly occur (Beyer 1968; Kaartvedt et al. 2009). The study comprised continuous acoustic measurements for 4 months during winter and spring 2007 2008 , supplemented by intermittent field campaigns. We also had access to results from daily measurements of fluorescence for an adjacent part of the Oslofjord for the whole study period. 
Continuous records-An upward-looking, bottommounted Simrad EK60 echo sounder equipped with a $200 \mathrm{kHz}$ depth-resistant transducer (ES200-7CD) was deployed at approximately $150 \mathrm{~m}$ depth $\left(59.792171^{\circ} \mathrm{N}\right.$, $10.726776^{\circ} \mathrm{E}$; same location as fig. 1 in Klevjer and Kaartvedt 2011). The transducer had a $7^{\circ}$ beam width, giving a radius of the acoustic beam of $6.1 \%$ compared to the range, and a footprint at the surface of $264 \mathrm{~m}^{2}$. The submerged transceiver was kept in a pressure-proof casing and was powered from land via $800 \mathrm{~m}$ of cable. Modems provided a full Ethernet connection over the cable to shore, where a laptop running the software ER60 stored the raw data for later analysis. The echo sounder was calibrated by a standard $13.7 \mathrm{~mm}$ copper sphere near the surface prior to deployment (Foote et al. 1987). The echo sounder was collecting data from 06 December 2007 to 17 April 2008 with a ping rate of $2 \mathrm{~s}^{-}$and pulse length of $0.256 \mathrm{~ms}$. The source level was set to $222.1 \mathrm{~dB}$ re $1 \mu \mathrm{Pa}$ at $1 \mathrm{~m}$.

Data on fluorescence were provided by the Norwegian Institute for Water Research (NIVA). Their Ferrybox project (www.ferrybox.no; Petersen et al. 2011) samples chlorophyll $a(\mathrm{Chl} a)$ fluorescence daily by utilizing fluorometers on ferries in regular traffic. We used these chlorophyll values $(4 \mathrm{~m}$ depth) from an adjacent station (around $8 \mathrm{~km}$ away) in the Oslofjord (59.80-59.83 N, $10.597-10.558 \mathrm{E}$ ) to assess the timing and magnitude of the spring bloom.

Sampling campaigns - The remaining sampling was carried out from the University of Oslo R/V Trygve Braarud 12-13 December 2007, and 14 January, 12 February, and 17-18 April 2008. Temperature and salinity were measured with a Falmouth Scientific Instruments conductivity, temperature, and depth probe (CTD), also equipped with water samplers and an uncalibrated fluorometer. Water from these samplers was later analyzed for oxygen content, using the Winkler method. Oxygen was not measured in April. Data from the echo sounders onboard R/V Trygve Braarud (Simrad EK $50038 \mathrm{kHz}$ and $120 \mathrm{kHz}$ ) together with the bottom-mounted EK60 were used to select sampling depths for a pelagic trawl, equipped with a Scanmar opening and closing cod-end (Engås et al. 1997). We used the same trawl and similar trawling procedures as described in Klevjer and Kaartvedt (2011). The trawl had an estimated opening area of $\sim 100 \mathrm{~m}^{2}$, with a $20 \mathrm{~cm}$ mesh size near the opening, declining to $1 \mathrm{~cm}$ at the rear part and $3 \mathrm{~mm}$ in the cod-end. The trawl was towed horizontally at 2 knots and was depth monitored during sampling with a Scanmar depth sensor. No trawling was performed in the severely hypoxic waters below $75 \mathrm{~m}$ as the acoustic data showed that this part of the water column was devoid of larger organisms. Absolute quantification of trawl catches per volume is not feasible, and we here use the relative unit "liters per minute of trawling" for comparison between the $\sim 10$ min tows. In total, 17 depth-resolved trawl samples were obtained throughout the water column during the day on 12-13 December, 14 January, and 17 April. To make a summary of the catches, we divided the water column into intervals of $10-15 \mathrm{~m}$ and averaged the catches from all samples within those intervals. Although 12 December was also allocated to night sampling, these data were discarded due to technical problems with the trawl.

Mesozooplankton were collected via depth-stratified vertical hauls with a $200 \mu \mathrm{m}$ plankton net (Working Party No. 2 [WP2]) equipped with a Nansen closing device and operated by a messenger. Samples were taken in intervals every $20 \mathrm{~m}$ down to $100 \mathrm{~m}$ and at $100 \mathrm{~m}$ to $150 \mathrm{~m}$. In addition to FPs, all animals were counted, but only results on animals with a size like Calanus finmarchicus and $C$. helgolandicus copepodite stage $\mathrm{V}$ and larger and with $n>1$ are presented. The length and width of FPs collected in the net samples were measured in a microscope even if the FP looked fragmented.

Acoustic post-processing-Acoustic targets allocated to FPs were quantified by measuring their acoustic backscatter and by counting acoustic tracks of individual FPs per time. Acoustic volume backscattering strength $(\mathrm{Sv}, \mathrm{dB})$ is the summation of the sound backscatter contribution from all targets within a sampling volume scaled to $1 \mathrm{~m}^{3}$. Target strength (TS, dB) is the sound backscatter from one individual target and is a proxy for size of the target, and the relationship can be determined by theoretical modeling and/or direct measurements. This has yet to be done for FPs, and the relationship between TS and size of a pellet is currently unknown.

We measured the Sv in a layer 5-10 m away from the transducer, while tracking individual FPs in three different layers. There was some hydrolysis of the echo sounder rig that temporarily created small gas bubbles rising in the lower part of the echogram. This problem was most extensive in February and, together with electrical noise, made us discard February from quantitative analyses of Sv.

Krill concentrations were measured daily from 1 February to 16 April by integration of the acoustic backscatter of the krill scattering layer between 11:00 h and 12:00 $\mathrm{h}$ coordinated universal time (UTC). The measurement time was chosen for the best separation of krill and fish. The results are shown as nautical area scattering coefficient and are converted to individuals per square meter by using an average krill TS of $-72.3 \mathrm{~dB}$. This TS is based on in situ measurements of krill at $120 \mathrm{kHz}$ in the Oslofjord (Klevjer and Kaartvedt 2006). Demer (2004) found virtually the same krill TS values for $120 \mathrm{kHz}$ and $200 \mathrm{kHz}$.

The sinking speeds of particles were assessed in two ways: measured from individual traces on echograms and automatic target tracking (TT) of individual particles using specialized software. The speeds from echograms were measured from the average sinking trend of all visible individual traces of FPs around dawn at 100-150 m depth. This trend was clearly visible in 22 days during March.

TT works by grouping individual echoes into tracks utilizing information on the proximity of sequential echoes in determining the tracks. In this way, a moving particle can be followed in space and time (i.e., as it moves through the acoustic beam). TT was also used to get a more robust average TS from all the individual echoes in a track. Conservative tracking criteria were used and, in order to accept a track, a minimum of 20 echoes were required with 
no more than a maximum of one consecutive echoes missing. The maximum depth difference between two pings was set to $30 \mathrm{~cm}$. All TT was done in the software Sonar 5 Pro version 6.0.0, and the single echoes were detected using the cross filter detector with default parameters (Balk and Lindem 2012). The lower echo detection threshold was set to $-120 \mathrm{~dB}$, which required a modification of the standard Sonar 5 Pro software. Sinking velocities of the tracks were calculated between start and stop of the track. Only sinking tracks with TS of less than $-80 \mathrm{~dB}$ were accepted, excluding larger targets, which we assume were too big to be FPs.

We performed TT for three separate vertical strata, 2$5 \mathrm{~m}, 5-10 \mathrm{~m}$, and $10-40 \mathrm{~m}$ range from the transducer, to include different sizes of sinking particles. The range will affect the results, as weak targets will fall below the detection threshold at a distance from the transducer and cause so-called threshold-induced bias (Weimer and Ehrenberg 1975). The implication is that the smallest particles will only be recorded close to the transducer and the acoustic axis. In addition, the TS distributions at longer range will be shifted toward larger particles, either because of the effects of erroneously stronger multiple echoes or because the progressively larger volume of the beam increases the chances of observing sparsely distributed large particles. Therefore, the different ranges will contain samples of different size ranges of particles.

Echograms were made by plotting the calibrated EK60 data in Matlab. All the times are given in UTC; local time is $\mathrm{UTC}+1$ and, during daylight saving time at the last part of the study, UTC +2 .

\section{Results}

Hydrography - The temperature, salinity, oxygen, and Chl $a$ values were relatively stable below $30 \mathrm{~m}$ during the study period (Fig. 1). The temperature increased with depth in the upper part of the water column, from a surface temperature of $\sim 1-3^{\circ} \mathrm{C}$ to about $9^{\circ} \mathrm{C}$ at $20 \mathrm{~m}$, and then it was fairly constant down to $60 \mathrm{~m}$ before declining to a homogenous basin water temperature of $7.9^{\circ} \mathrm{C}$ (Fig. 1). Salinity increased rapidly by depth in the upper $20 \mathrm{~m}$, then more slowly, until it stabilized at a basin water salinity of 33.4 (Fig. 1).

Oxygen values decreased rapidly by depth in the upper $20 \mathrm{~m}$, were fairly constant at $\sim 2 \mathrm{~mL} \mathrm{O}_{2} \mathrm{~L}^{-1}$ down to $50 \mathrm{~m}$, and then decreased to $\sim 0.5 \mathrm{~mL} \mathrm{O}_{2} \mathrm{~L}^{-1}$ at $\sim 60 \mathrm{~m}$ (Fig. 1). The deep water was severely hypoxic, with oxygen concentrations always below $0.5 \mathrm{~mL} \mathrm{O}_{2} \mathrm{~L}^{-1}$. Deeper than $100 \mathrm{~m}$, the oxygen concentration decreased to below $0.2 \mathrm{~mL}$ $\mathrm{O}_{2} \mathrm{~L}^{-1}$ in February. There were no oxygen measurements later than February; but, judging by the temperature and salinity, there was no input of new bottom water in the basin, and the oxygen levels would therefore continue to decrease slowly.

Fluorescence-The Chl $a$ concentrations as measured at the four CTD casts were low during the winter (Fig. 1), but in April the measurements peaked just above $4 \mu \mathrm{g} \mathrm{L} \mathrm{L}^{-1}$

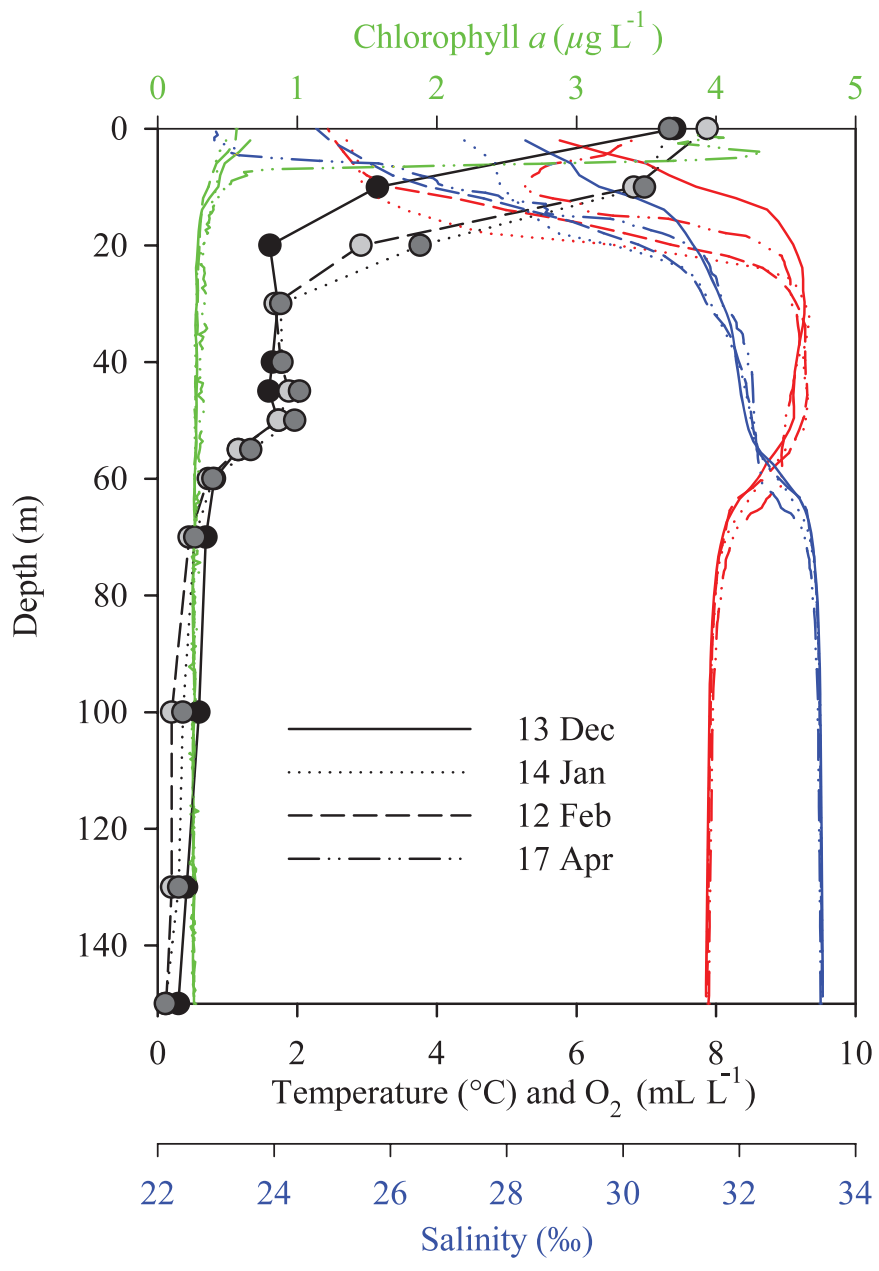

Fig. 1. Data from four CTD casts. Chl $a$, temperature, and salinity are marked as green, red, and blue, respectively. Oxygen is marked as black with black dots for 13 Dec 2007, dark gray dots 14 Jan 2008, and light gray dots for 12 Feb 2007.

around $4 \mathrm{~m}$ depth. Values in deep water were always low at the time of the measurements.

The continuous long-term Chl $a$ (fluorescence) measurements at $4 \mathrm{~m}$ depth showed very low concentrations during winter, starting to increase slowly in late February (Fig. 2). In early March, the concentrations increased rapidly and peaked at above $20 \mu \mathrm{g} \mathrm{L}^{-1}$ in mid- to late March, subsequently decreasing rapidly to around $5 \mu \mathrm{g} \mathrm{L}^{-1}$ in early April (Fig. 2). The concentration remained below $5 \mu \mathrm{g} \mathrm{L}^{-1}$ for the rest of the year (not all data shown). When comparing the fluorometer data at $4 \mathrm{~m}$ depth at the CTD sampling station and the continuous measurements at the same dates, the difference was never greater than $0.3 \mu \mathrm{g} \mathrm{L}^{-1}$.

Vertical net sampling - A summary of the WP2 catches is presented in Table 1. Calanus spp. dominated the WP2 net catches in numbers $(71 \%)$ and even more in biomass, since most of the other numerous animals were smaller copepods. The vast majority of the overwintering Calanus inhabited the hypoxic waters below $60 \mathrm{~m}$, yet with their distribution shifting gradually upward in the course of winter and spring (Table 1). 


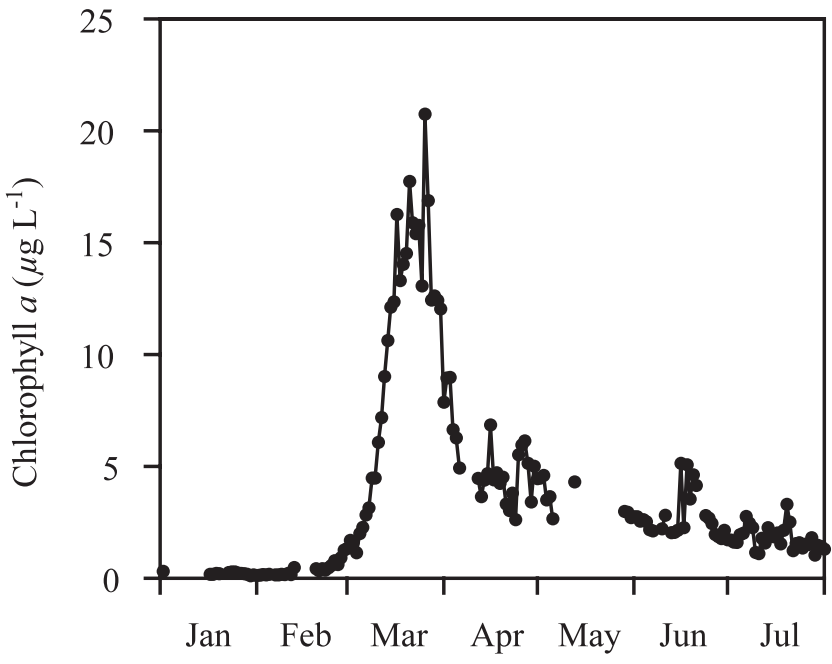

Fig. 2. Daily measurements of Chl $a$ concentrations at $4 \mathrm{~m}$ depth.

A total of 453 FPs (39 FPs $\mathrm{m}^{-3}$ ) were collected in a daytime net tow from $100 \mathrm{~m}$ to $148 \mathrm{~m}$ on 18 April, almost the exclusive catch at the time. This was the only time FPs were present in the net, and it was the only net tow during high Chl $a$ concentrations at the surface; unfortunately, we had no net tows during March. The maximum length of the FPs was $2 \mathrm{~mm}$, but most seemed broken at the ends. These fragmented FPs were cylindrical, with a mean length of $0.72 \mathrm{~mm}$ (standard deviation $[\mathrm{SD}]=0.32$ ), a mean width of $0.19 \mathrm{~mm}(\mathrm{SD}=0.04)$, and a mean calculated volume of $0.022 \mathrm{~mm}^{3}(\mathrm{SD}=0.016)$. The size and appearance of these pellets indicated that they were krill pellets and were too large to be copepod FPs (see Discussion).

Pelagic trawling-The dominant species in the pelagic trawl were krill (M. norvegica) and the clupeid fishes sprat (Sprattus sprattus) and herring (Clupea harengus; Table 2). Also some whiting (Merlangius merlangus) were captured. The volumes of clupeids and krill captured were fairly similar, whereas, numerically, the krill prevailed by up to two orders of magnitude. Over $\sim 90 \%$ of the biomass in these daytime samples was caught at 50-60 m.

Long-term acoustic records-The krill and clupeids could be easily distinguished acoustically (Fig. 3). Krill formed a diffuse scattering layer inhabiting $\sim 50-60 \mathrm{~m}$ depth in the
Table 2. Average pelagic trawl catches. Clupeids and krill are shown as volume organism per minute, whereas whiting is shown as individual (ind.) per minute. Standard deviation in parentheses.

\begin{tabular}{|c|c|c|c|c|}
\hline Depth (m) & $\begin{array}{l}\text { Clupeids } \\
\left(\mathrm{L} \mathrm{min}^{-1}\right)\end{array}$ & $\begin{array}{c}\text { Krill } \\
\left(\mathrm{L} \mathrm{min}^{-1}\right)\end{array}$ & $\begin{array}{l}\text { Whiting } \\
\text { (ind. } \min ^{-1} \text { ) }\end{array}$ & $n$ \\
\hline $35-50$ & $0.07(0.04)$ & $0.05(0.1)$ & 0 & 4 \\
\hline $50-60$ & $1.29(1.09)$ & $0.98(1.15)$ & $1.22(1.08)$ & 6 \\
\hline $60-75$ & 0 & $0.10(0.01)$ & $0.01(0.03)$ & 7 \\
\hline
\end{tabular}

daytime and migrating toward the surface at night throughout the entire study period. The fish were schooling in the daytime, and their distribution on average became deeper at night, with part of the population moving downwards toward what appeared to be their lower tolerable oxygen concentration.

No fish or krill were detected acoustically below $\sim 60$ $70 \mathrm{~m}$ depth, where oxygen levels were below $0.5 \mathrm{~mL} \mathrm{O}$ $\mathrm{L}^{-1}$. In the absence of larger animals, the acoustic backscattering was low and never exceeded $-80 \mathrm{~dB}$ (which is why the echogram in Fig. 3 appears white in the lower part of the water column). The oxygen concentration decreased further with depth, and 5-10 $\mathrm{m}$ off the bottom the background backscattering was very weak $(<-100 \mathrm{~dB})$ all through the study period.

Through February and early March, backscatter levels below $100 \mathrm{~m}$ depth continued to weaken, and the mean $\mathrm{Sv}$ from 100 to $140 \mathrm{~m}$ depth decreased from $-88 \mathrm{~dB}$ to $-98 \mathrm{~dB}$ during February. This can be visualized using low acoustic thresholds (Fig. 4) and can likely be explained by exclusion or reduction in the occurrence of the smaller living organisms when the water gradually became more hypoxic, as exemplified by the gradually shallower distribution of Calanus spp. through winter (Table 1). These conditions made it ideal to study small particles with very weak echoes (which otherwise might have been masked by stronger targets). A weak pulse of acoustic targets that were slowly sinking toward the bottom from waters above was first detected at dawn on February 23. Daily pulses of sinking material became progressively more evident in the course of the subsequent month (Fig. 4). The pulses appeared at nighttime with $\mathrm{a} \sim 3-6 \mathrm{~h}$ time delay after onset of darkness and disappeared $\sim 6-8 \mathrm{~h}$ after sunrise when the last particles hit the bottom. Thereafter, sinking material was no longer recorded until the next night. An example of this pattern is shown in Fig. 5A, and, when zooming in at

Table 1. Concentrations $\left(\mathrm{m}^{-3}\right)$ of animals and fecal pellets at different depth intervals caught in WP2 net. Empty or missing fields indicate no catch.

\begin{tabular}{|c|c|c|c|c|c|c|c|}
\hline & Date & $150-100 \mathrm{~m}$ & $100-80 \mathrm{~m}$ & $80-60 \mathrm{~m}$ & $60-40 \mathrm{~m}$ & $40-20 \mathrm{~m}$ & $20-0 \mathrm{~m}$ \\
\hline & $12 \mathrm{Feb}$ & 50.8 & 791.6 & 232.8 & 46.1 & 3.0 & 1.8 \\
\hline Amphipods & All & - & - & - & 2 & 0.2 & 0.2 \\
\hline Krill & All & - & - & - & - & 0.4 & 0.2 \\
\hline Chaetognaths & All & - & 0.8 & 0.4 & 1.2 & 0.6 & - \\
\hline Fecal pellets & $18 \mathrm{Apr}$ & 38.6 & - & - & - & - & - \\
\hline
\end{tabular}

${ }^{a}$ CI-CVI, copepodite stages I to VI. 


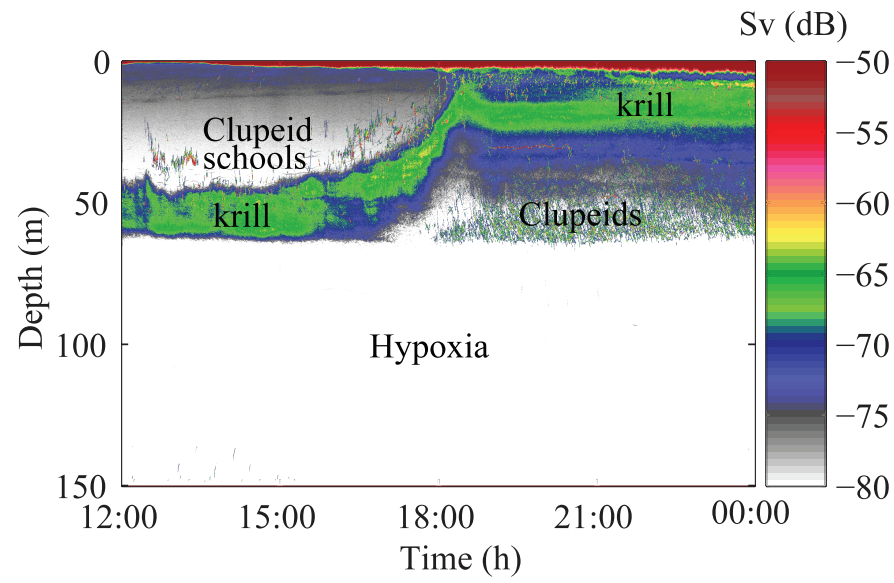

Fig. 3. An example of the distribution of clupeid fish and krill, shown in a $12 \mathrm{~h}$ echogram from 24 March. All larger animals stayed above the hypoxic water (white) starting at 60-70 m depth. Krill migrated to the surface at night. Clupeids schooled above the krill in daytime, and a major part of the clupeids stayed just above the hypoxic water at nighttime. The threshold is set to $-80 \mathrm{~dB}$, and no weaker sound scatterers appear.

higher resolutions, individual sinking particles appeared as oblique lines on the echograms (Fig. 5B,C).

A total of over 60,000 individual tracks were recorded with TT from 01 February to 17 April. All the tracked particles were relatively small, as suggested by their low TS
(Table 3; Fig. 6). The smallest particles were only possible to detect at shorter ranges, and mean TS therefore clearly increased with range (Fig. 6; Table 3). This gave samples of different size groups of FPs at different ranges, i.e., a $14.1 \mathrm{~dB}$ increase in the average TS between ranges of $2-5 \mathrm{~m}$ and 10-40 $\mathrm{m}$ (Table 3 ).

The occurrence of tracks corresponded well with the timing of the pulsed sedimentation (Fig. 7). The stronger tracks at the longest ranges $(10-40 \mathrm{~m})$ were the first to be recorded each night (Fig. 7). These tracks are visible as long darker lines in the first $3 \mathrm{~h}$ of Fig. 5B, whereas the particles tracked at $2-5 \mathrm{~m}$ are visible as small dots in the deepest part later at night (Fig. 5C). The particles tracked from $5 \mathrm{~m}$ to $10 \mathrm{~m}$ appeared to be a mix between those from the two other ranges. All the daily variations in backscatter from the pulses and particles tracked for the last part of the study period are shown in Fig. 8, where the regular daily variation is most apparent in the number of tracked particles.

The pattern of recurrent diel pulses continued until 28 March, when a strong pulse that lasted over $2 \mathrm{~d}$ occurred (Figs. 4, 7, 8). During this event, it was not possible to detect individual particles in the echograms; and particles were hardly resolved for TT, so that the pulse was characterized by fewer tracks (Figs. 7, 8). This suggests that the pulse contained particles that were smaller and/or occurred in higher densities than earlier (as high densities prevent the resolution of individual targets). After this $2 \mathrm{~d}$
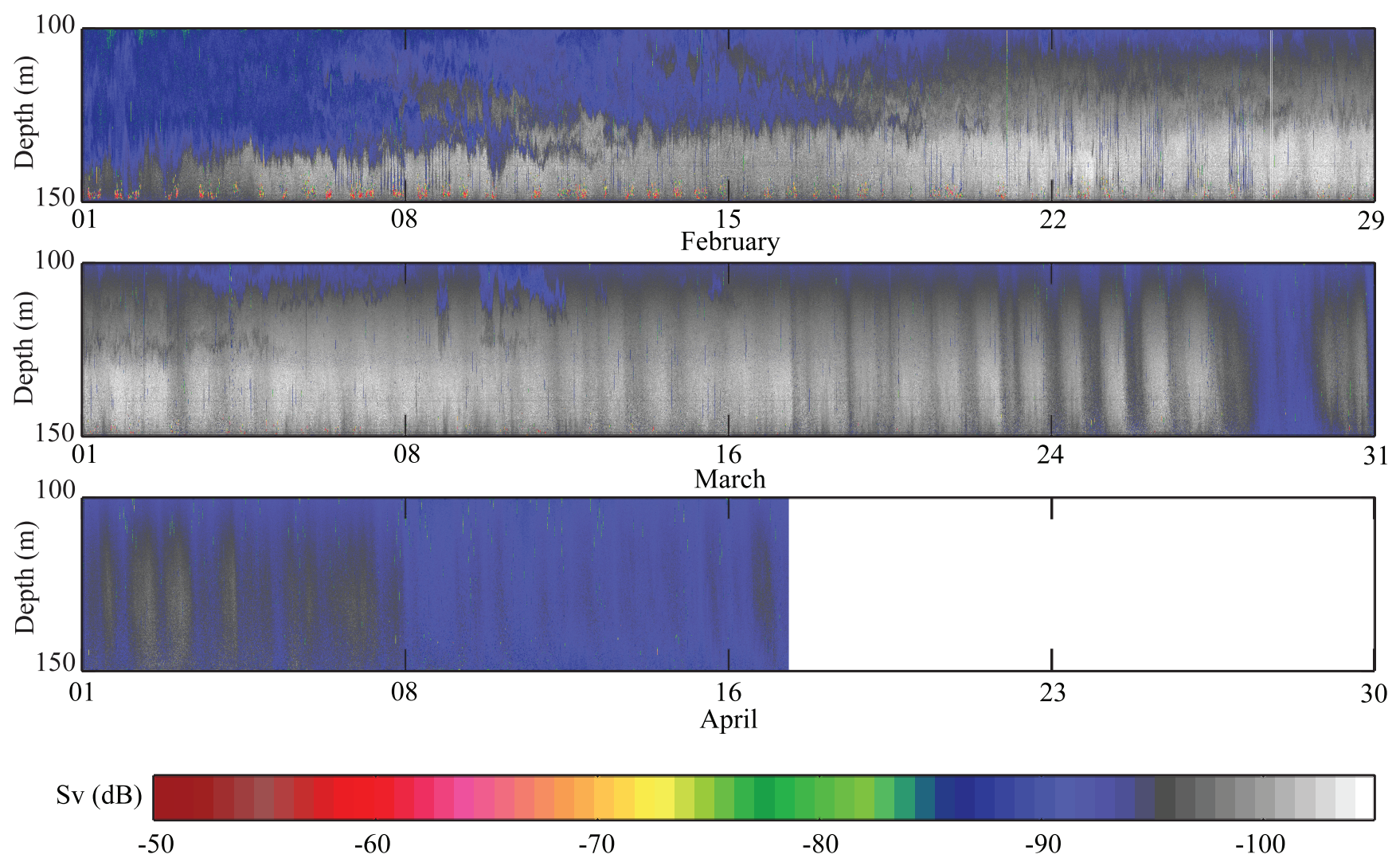

Fig. 4. Continuous echogram from 01 February to 17 April, showing the deepest part of the water column. Threshold -105 dB. Daily pulses became more apparent through March. Strong red echoes near the bottom in February are gas bubbles emitted from the acoustic rig (hydrolysis). 

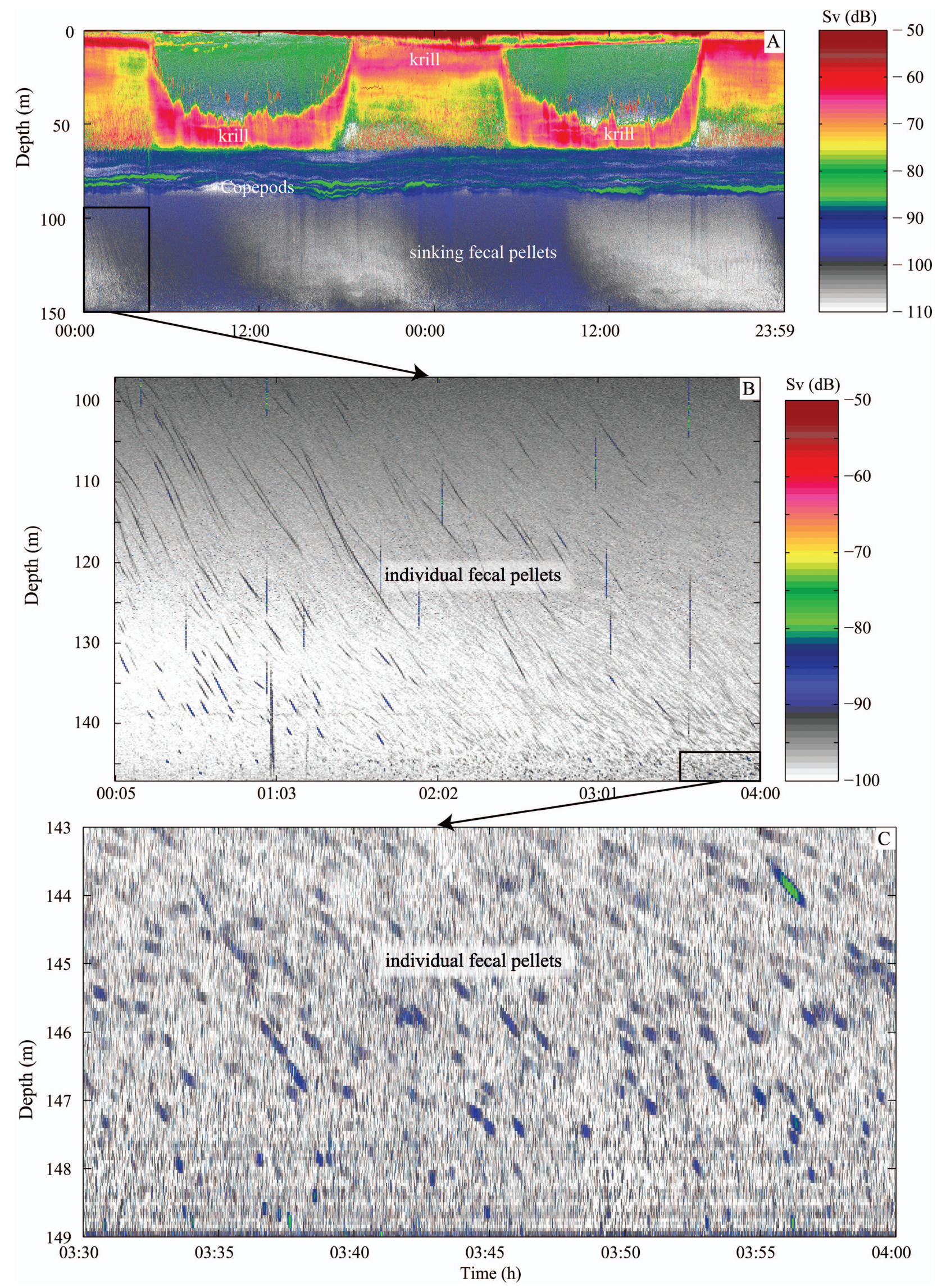
Table 3. Average sinking speeds and TS of tracked particles.

\begin{tabular}{|c|c|c|c|c|c|c|}
\hline Date & Range (m) & $\begin{array}{l}\text { Average sinking } \\
\text { speed }\left(\mathrm{cm} \mathrm{s}^{-1}\right)\end{array}$ & SD & $\begin{array}{l}\text { Average sinking } \\
\text { speed }\left(\mathrm{m} \mathrm{d}^{-1}\right)\end{array}$ & $\begin{array}{l}\text { Average } \\
\text { TS (dB) }\end{array}$ & $n$ \\
\hline $01 \mathrm{Feb}-17 \mathrm{Apr}$ & $2-40$ & 0.72 & 0.48 & 622 & -88.8 & 60,187 \\
\hline $01 \mathrm{Feb}-17 \mathrm{Apr}$ & $2-5$ & 0.57 & 0.34 & 492 & -99 & 26,155 \\
\hline $01 \mathrm{Feb}-17 \mathrm{Apr}$ & $5-10$ & 0.75 & 0.45 & 648 & -92.7 & 12,566 \\
\hline $01 \mathrm{Feb}-17 \mathrm{Apr}$ & $10-40$ & 0.88 & 0.58 & 760 & -84.9 & 21,466 \\
\hline 01-26 Mar & $2-40$ & 0.66 & 0.53 & 570 & -90.3 & 16,451 \\
\hline 01-26 Mar & $2-5$ & 0.49 & 0.31 & 423 & -103.3 & 8434 \\
\hline 01-26 Mar & $5-10$ & 0.65 & 0.53 & 562 & -96 & 2744 \\
\hline 01-26 Mar & $10-40$ & 0.93 & 0.68 & 804 & -85.7 & 5275 \\
\hline 28 Mar-17 Apr & $2-40$ & 0.74 & 0.4 & 639 & -89.1 & 34,397 \\
\hline $28 \mathrm{Mar}-17 \mathrm{Apr}$ & $2-5$ & 0.62 & 0.34 & 536 & -97.6 & 15,449 \\
\hline $28 \mathrm{Mar}-17 \mathrm{Apr}$ & $5-10$ & 0.79 & 0.39 & 683 & -91.8 & 8544 \\
\hline $28 \mathrm{Mar}-17 \mathrm{Apr}$ & $10-40$ & 0.88 & 0.43 & 760 & -84.9 & 10,405 \\
\hline
\end{tabular}

event, the number of tracks increased, the sedimentation pattern changed and became more continuous throughout day and night, and sinking tracks at $2-5 \mathrm{~m}$ range also became common during the daytime (Figs. 8, 9). However, the daily timing of stronger tracks $(10-40 \mathrm{~m})$ did not change much and mainly occurred at night from 23:00 $\mathrm{h}$ to 06:00 h throughout the study period (Fig. 10).

The first seasonal detection of sinking particles corresponded well with initiation of the spring bloom, and both the volume (total) acoustic backscatter created by the sinking particles and number of tracked particles $(2-5 \mathrm{~m})$ increased in parallel with the bloom until it peaked (culminated) on 26 March (Fig. 11A). There was a clear linear correlation between chlorophyll concentrations and mean daily backscatter at $5-10 \mathrm{~m}$ range from the transducer $\left(R^{2}=0.66\right)$ as well as with the daily number of tracks at $2-5 \mathrm{~m}\left(R^{2}=0.59\right)$ from initiation of the bloom until the chlorophyll concentrations peaked. After the peak, the correlations broke down. In the same time period there was no similar trend in the krill concentration present at the study site (Fig. 11B), but there was a strong increase during the last $3 \mathrm{~d}$ of the registration period. The average krill concentration was 81 animals per square meter (57 excluding the last $3 \mathrm{~d}$ ), and most of the day-to-day variation was caused by the occurrence of krill schools at the time of measurement (11:00 h-12:00 h UTC) in the krill scattering layer.

Sinking speeds and vertical flux - Sinking speeds were measured from traces on the echogram and from acoustic TT of individual particles. The general trend of sinking particles on echograms in March gave a mean sinking speed of $0.52 \mathrm{~cm} \mathrm{~s}^{-1}(\mathrm{SD}=0.06)$. The sinking speeds from TT are summarized in Table 3. In general, the vertical speed followed the increase in TS with range from the transducer, and the average sinking speed for the period 1-26 March was $0.49,0.65$, and $0.93 \mathrm{~cm} \mathrm{~s}^{-1}$ at a range of, respectively,
$2-5,5-10$, and $10-40 \mathrm{~m}$ from the transducer. This gives ranges of daily average sinking distances between $423 \mathrm{~m}$ and $804 \mathrm{~m}$.

Both the TS and sinking speed increased after 28 March for tracks between $2 \mathrm{~m}$ and $10 \mathrm{~m}$ range (Table 3). Tracks between $10-40 \mathrm{~m}$ remained relatively unchanged. Sinking speed increased $0.14 \mathrm{~cm} \mathrm{~s}^{-1}$ on average (Table 3). A summary of all the daily averages at $2-5 \mathrm{~m}$ through the study period is presented in Fig. 12.

TS explained only $13 \%$ of the variability in sinking speed when a linear correlation was done on all the tracks. However, the relationship between TS and sinking speed increased dramatically when all the velocities for specific TSs were binned and then these values were averaged (when $n$ was less than 100 the TS point was removed). This removed general noise and outliers and resulted in a linear correlation between TS and sinking speed that explained $97 \%$ of the variation (Fig. 13A). The relationship had the following equation: $\mathrm{TS}=42.5 \mathrm{v}-126.2$, where $\mathrm{v}$ is sinking speed in $\mathrm{cm} \mathrm{s}^{-1}$ and TS has a range from $-111 \mathrm{~dB}$ to $-80 \mathrm{~dB}$ (Fig. 13A). Using only tracks within a range of $2 \mathrm{~m}$ to $5 \mathrm{~m}$ gave a slower increasing linear relationship of TS $=$ $33.5 \mathrm{v}-121.7$, with $R^{2}=0.95$ and a smaller TS range $(-111$ to $-90 \mathrm{~dB}$; Fig. 13B).

Both recorded TS and sinking speed at $2-5 \mathrm{~m}$ range declined in the course of the night in the period before 28 March (Fig. 14), which was expected since faster sinking particles will hit the bottom first.

\section{Discussion}

This study revealed regular diel pulses of sedimenting particles that were associated with the arrival of krill $(M$. norvegica) in upper waters at night and that terminated subsequent to the return of krill to their daytime habitat in the morning. Our trawl catches identified that the dielly migrating scattering layers consisted of the krill $M$.

Fig. 5. Example of sinking pulses of fecal pellets in a $2 \mathrm{~d}$ echogram starting $24 \mathrm{March}$. With some time lag, the pulses correlate with the diel migration of krill foraging in upper waters at night. When zoomed in, it is possible to observe individual sinking particles, with the weakest particles only visible close to the transducer at the bottom. 

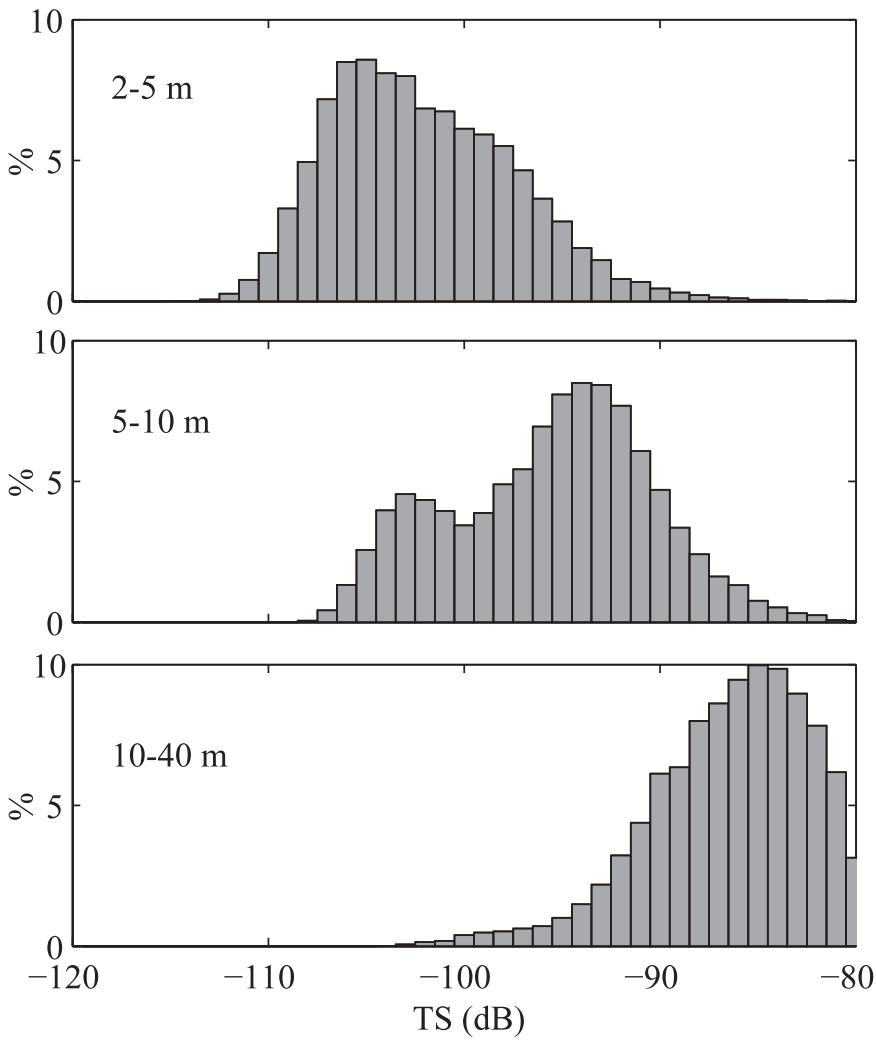

Fig. 6. Target strength histograms of particles tracked at three different ranges. norvegica and clupeids, in accordance with results from many years of sampling and acoustic studies in this location (Kaartvedt et al. 2009; Klevjer and Kaartvedt 2011; Solberg et al. 2012).

The diel pattern of sedimentation was initiated at the onset of the spring bloom, and it abated at the culmination of the bloom. We conclude that these dielly pulsed acoustic measurements reflect sinking FPs of the dielly migrating krill. The appearance and the size of the FPs caught in the net indicated that their origin was krill (Moore 1931; Pasternak et al. 2000; Wexels Riser et al. 2002). Wexels Risers et al. (2010) found that krill pellets contributed $>$ $90 \%$ of FP vertical carbon export in a Norwegian fjord during spring. The overwintering Calanus sp. possibly ascended to upper layers and grazed on the spring bloom during March; however, their pellets are much smaller than those of krill (Martens 1978; Youngbluth et al. 1989) and are therefore much weaker acoustic targets. Also, the sinking rates we measured appear too high to be copepod pellets (Turner 2002).

Feces from fish are not a likely explanation for the diel pulses of sedimenting material. Sprat may prey on dormant copepods, but they do so in the daytime (Kaartvedt et al. 2009); yet this winter the hypoxia-tolerant dormant copepods (Osgood and Checkley 1997) mainly occurred deeper, and in lower oxygen concentrations, than the sprat could tolerate most of the study period.

The hypoxic waters in Bunnefjorden, devoid of macroscopic life, enabled the use of very low $\mathrm{Sv}$ thresholds, thereby facilitating records of the weak pellet targets. Pellets of $M$. norvegica may reach a size of $\sim 10 \mathrm{~mm}$

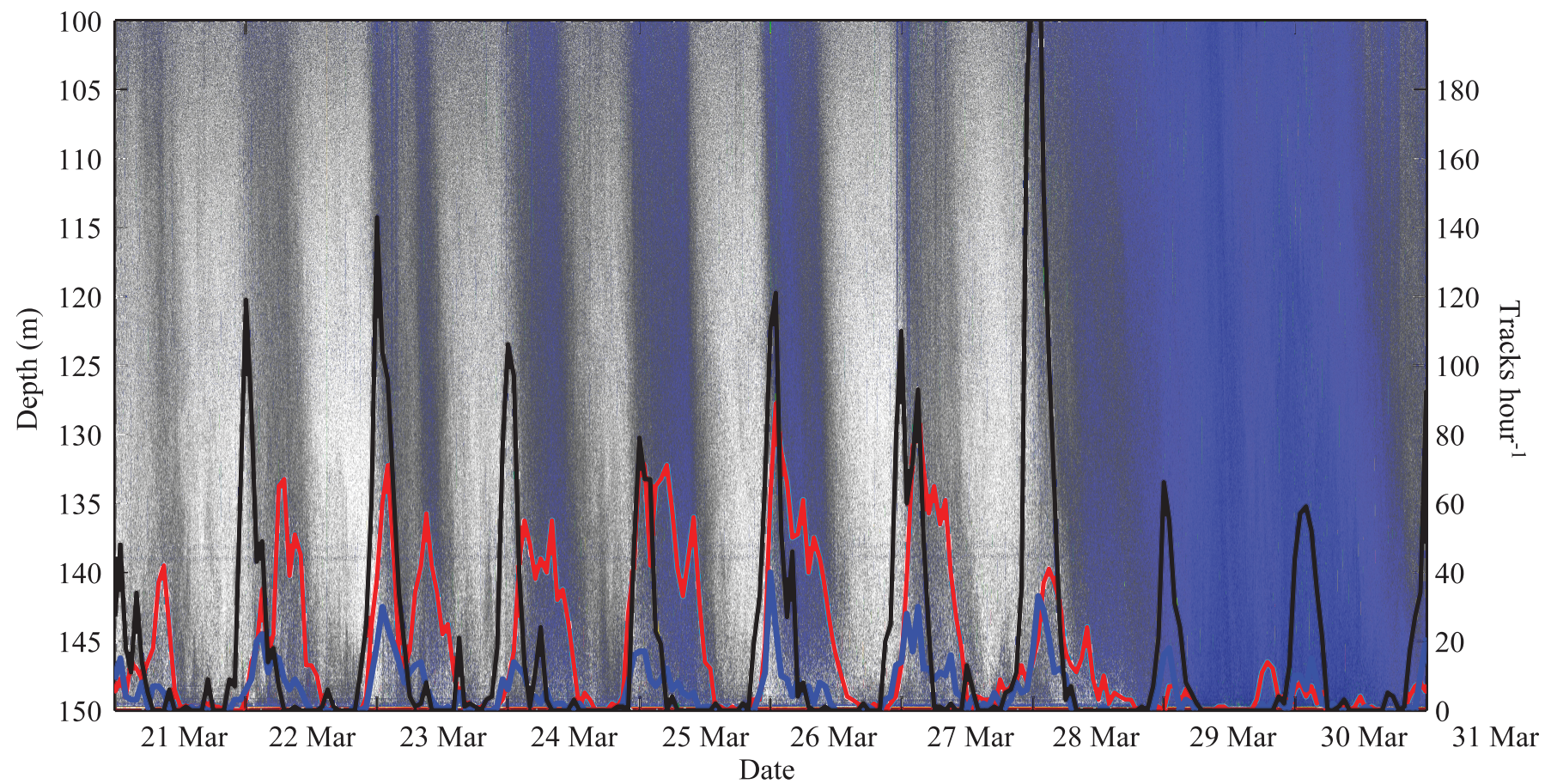

Fig. 7. Echogram from 21 to 31 March with a threshold of $-110 \mathrm{~dB}$. The overlaid lines represent the number of individually tracked particles per hour at $2.5 \mathrm{~m}$ (red), 5-10 m (blue), and 10-40 m (black) from the bottom. The shortest tracking ranges correspond best with the pulses, whereas tracks at the longest ranges occur before and at the start of the main pulses. Each date tick is located at midnight (UTC). 


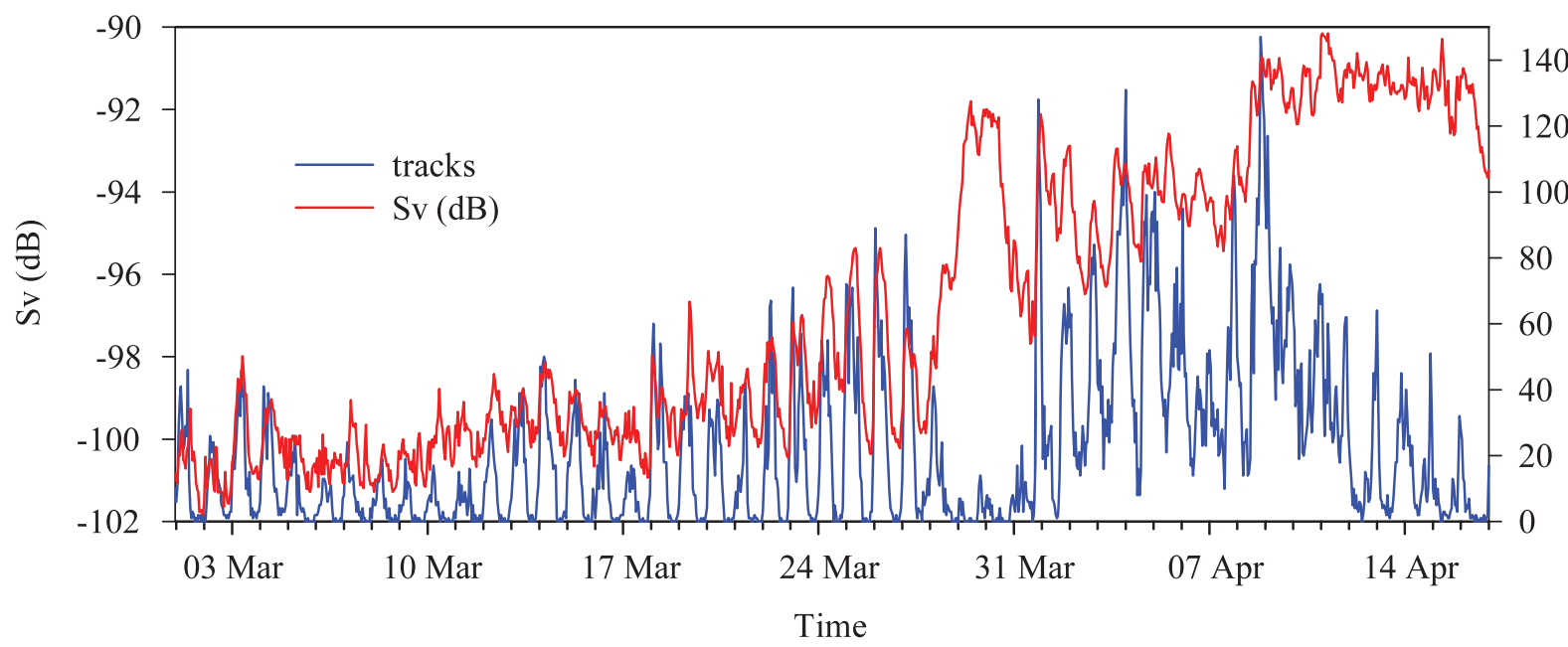

Fig. 8. Diel variation of mean backscatter (Sv) and tracked particles from 01 March to 17 April. Both lines are hourly averages, and midnight is marked as ticks.

(Youngbluth et al. 1989), and, although most FPs are smaller, this would make them acoustically visible at $200 \mathrm{kHz}$. The wavelength of the $200 \mathrm{kHz}$ echo sounder is about $7 \mathrm{~mm}$, and it detects objects equal to this and larger well. Objects much smaller than the wavelength can be detected, especially when they occur in higher concentrations; although, there is an exponential decrease in TS with size in this so-called Rayleigh scattering region (Horne and Jech 2005). Atkinson et al. (2012) found that krill FPs tend to sink at a horizontal angle, which will maximize their acoustic backscatter section and, thereby, their TS relative to their size.

FPs sampled from sediment traps are normally broken, and the number of fragments derived from one pellet can be as high as 6-8 (Wexels Riser et al. 2010). This implies that ex situ lengths reported in the literature may be underestimates; and, therefore, FP volumes or carbon weight are often used (Wexels Riser et al. 2010). FPs caught in our nets got rougher treatment than with more conventional sampling methods, and the length of the pellets does not reflect their true size; yet their width suggested their identity.

The marked diel signal with initiation of pellet production subsequent to krill arrival in upper waters is in accordance with numerous reports linking diel vertical migration among $M$. norvegica to herbivorous feeding in upper layers at night (Mauchline and Fisher 1969; Sameoto 1980; Simard et al. 1986), which was also observed during previous studies in the Oslofjord (Onsrud and Kaartvedt 1998; Kaartvedt et al. 2002). M. norvegica may prey on overwintering Calanus spp. in the daytime when their distributions overlap (Kaartvedt et al. 2002), but in the current study Calanus spp. overwintered in hypoxic waters beyond the reach of the krill during most of the study period. Whereas there likely was an increasing overlap in distributions as Calanus ascended from overwintering, $M$. norvegica appears to specialize as an herbivore during the spring bloom (Onsrud and Kaartvedt 1998; Kaartvedt et al. 2002).

The diel periodicity in sedimentation changed upon culmination of the bloom, with sedimentation more

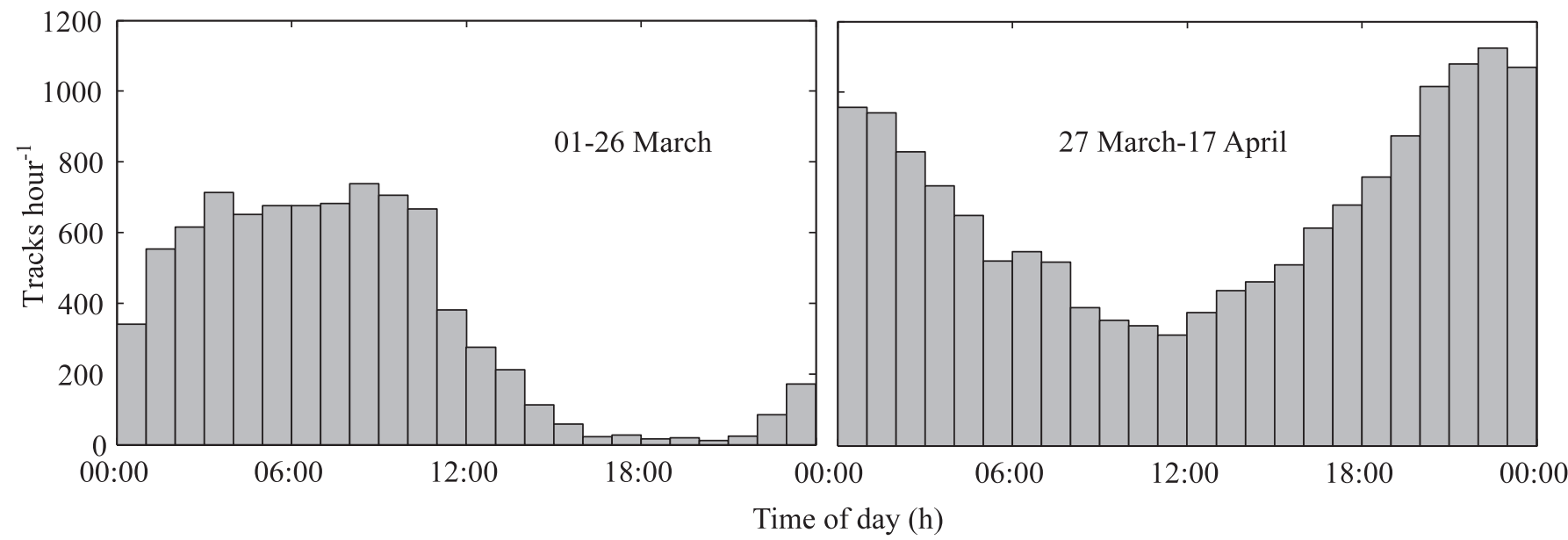

Fig. 9. Distribution of tracked particles per hour through the day at two different periods. Tracks from $2 \mathrm{~m}$ to $5 \mathrm{~m}$ range from the bottom. 


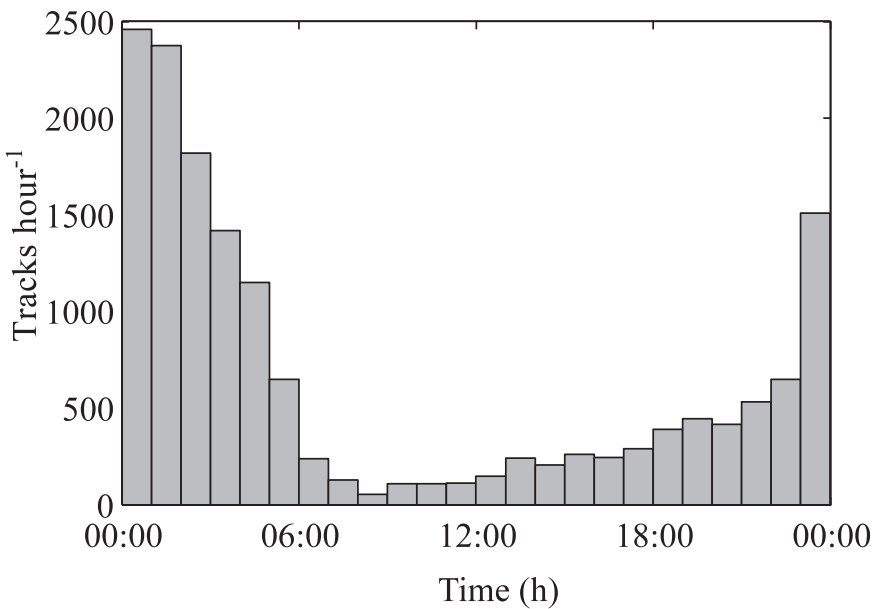

Fig. 10. Distribution of tracks through the day from 01 March to 17 April, with a range of $10 \mathrm{~m}$ to $40 \mathrm{~m}$ from the bottom. continuous throughout the day and with a peak earlier in the night (Fig. 9). The sudden and marked $2 \mathrm{~d}$ flux event at the culmination of the bloom (Figs. 4, 7, 8) may tentatively be ascribed to sedimenting aggregates of phytoplankton, as large aggregates may have been detected acoustically, particularly if holding enclosed gas bubbles. The spring bloom plankton community in the Oslofjord is dominated by diatoms (Kristiansen et al. 2001), and there are several reports on mass sedimentation of diatom blooms (Bodungen et al. 1981; Turner 2002) in which the formation of diatom aggregates enhances sedimentation (Riebesell 1991). Briggs et al. (2011) reported on an aggregate flux event at the height of a north Atlantic spring bloom, with aggregates of diatoms and resting spores sinking as a discrete pulse in the course of a few days. Sedimenting diatom blooms are reported to sink slower than FPs (range 100-150 $\mathrm{m} \mathrm{d}^{-1}$; Billett et al. 1983; Lampitt 1985), which will result in a pulse lasting for several days at the depths
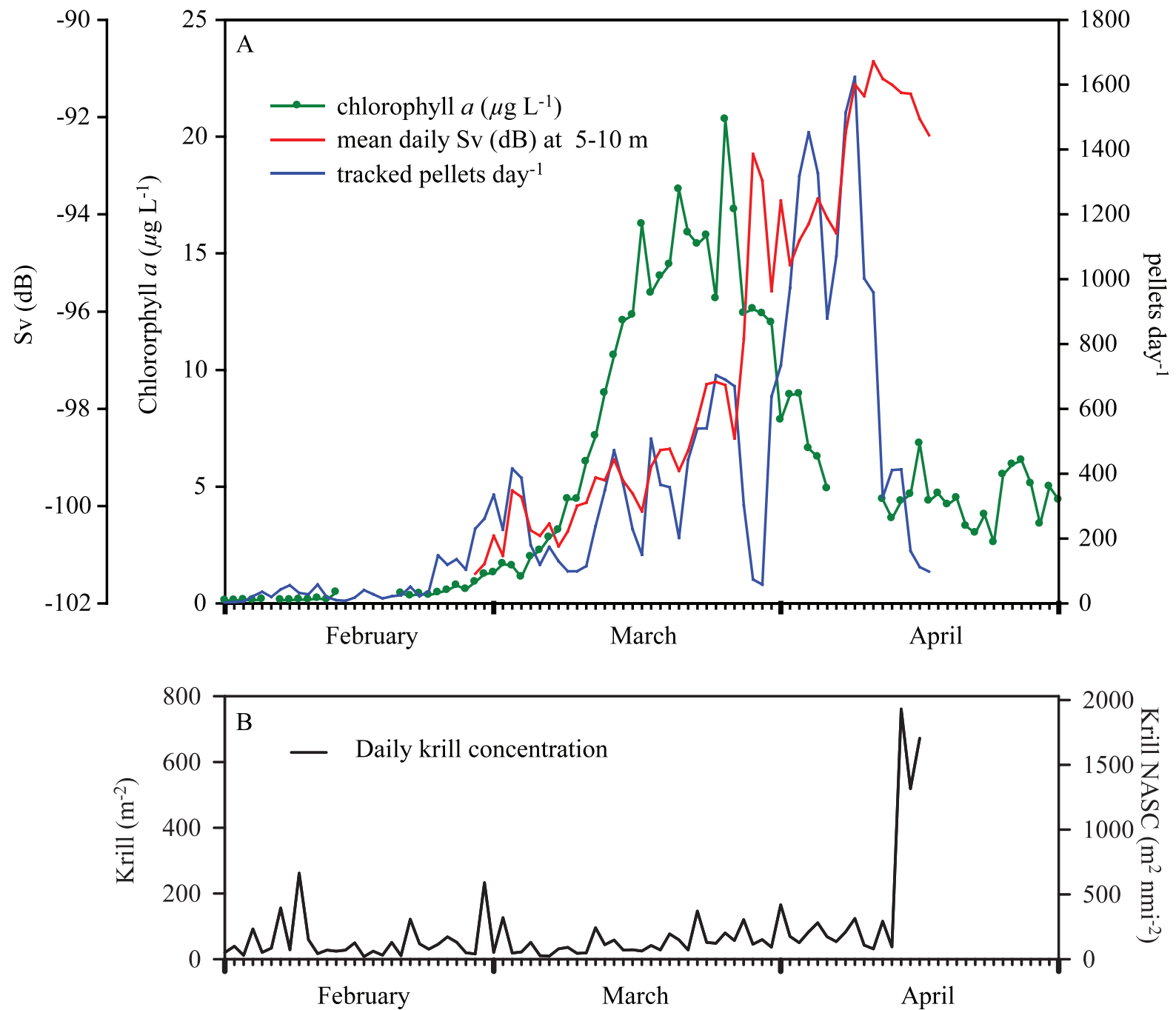

Date

Fig. 11. (A) Daily Chl $a$ measurements at $4 \mathrm{~m}$ depth, mean daily volume backscatter (Sv) at $140-145 \mathrm{~m}$ depth (5 to $10 \mathrm{~m}$ above the bottom), and number of acoustically tracked pellets per day (2-5 m above the bottom). (B) Daily daytime concentrations of krill measured by echo integration of the krill scattering layer and shown as individuals per square meter and nautical area scattering coefficient (NASC). 


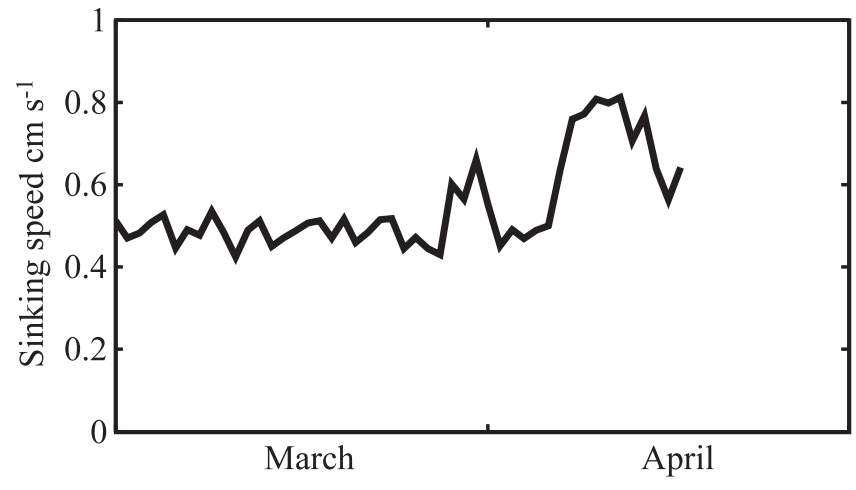

Fig. 12. Daily average sinking speed at $2-5 \mathrm{~m}$ range.

seen in this study. There was a change in the diel pattern of sedimentation subsequent to the pulse event, and a change in the diel feeding pattern of the krill may have contributed to the shift in timing. The rise and culmination of the spring bloom will have represented a change in absolute food availability but also likely a change in the vertical distribution of food, as decaying algae sinks to deeper water at the termination of the bloom. Accordingly, both Onsrud and Kaartvedt (1998) and Kaartvedt et al. (2002) found high daytime gut fluorescence values of krill in Oslofjord during spring. However, as the source of the acoustic signals (identity of sinking particles) is more
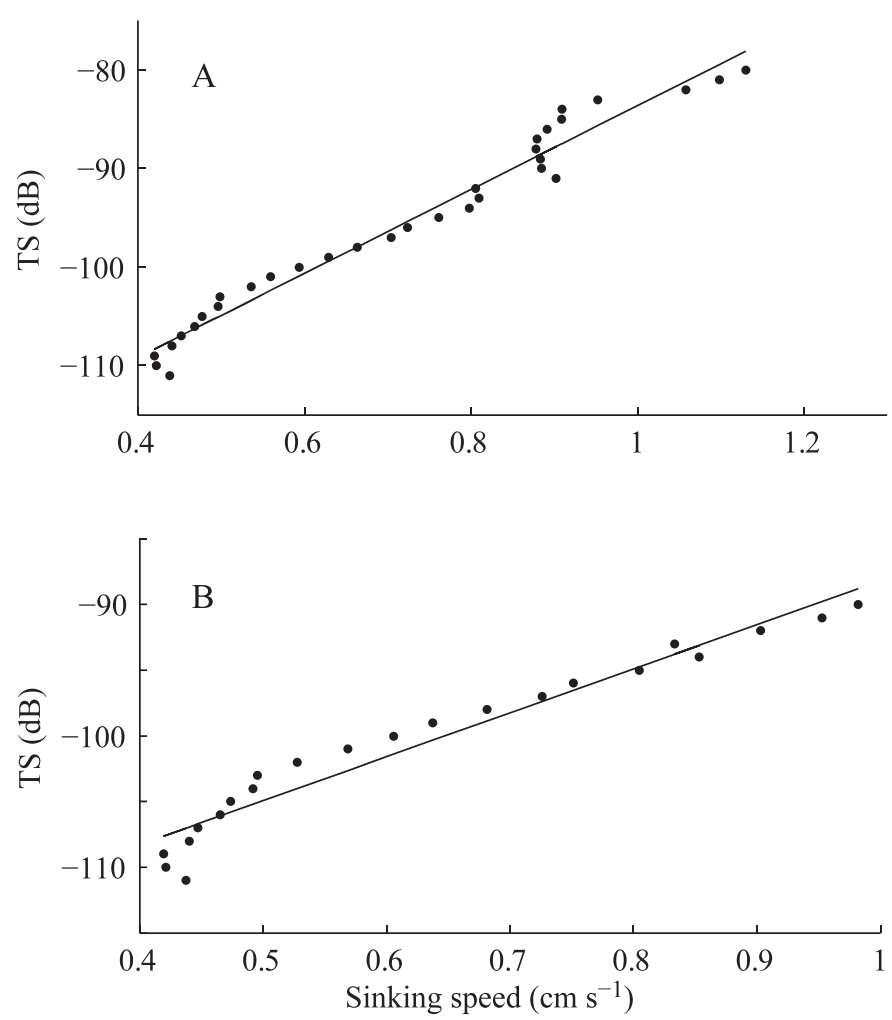

Fig. 13. Linear correlation between sinking speed and TS. Each point is average of all speeds for each $\mathrm{dB}$ of TS. (A) represents all particles tracked from $2 \mathrm{~m}$ to $40 \mathrm{~m}$ from the transducer and (B) particles tracked $2-5 \mathrm{~m}$ from the transducer.

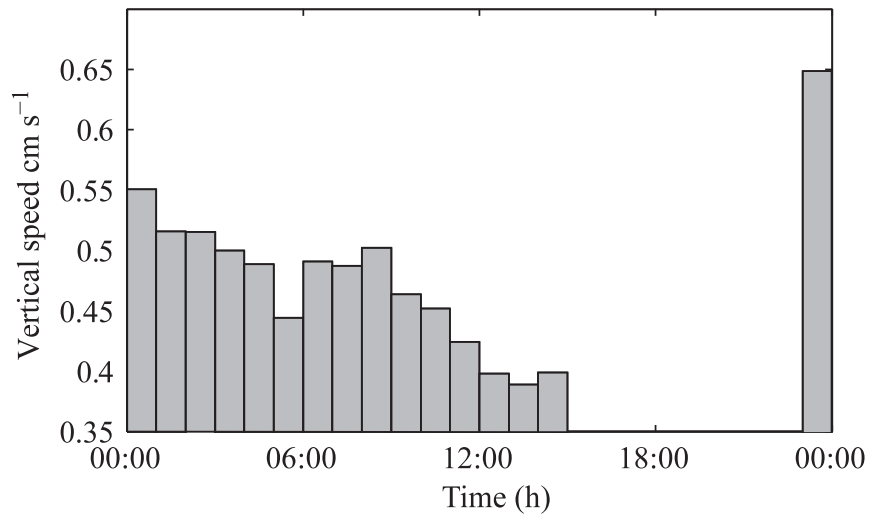

Fig. 14. Hourly sinking speed averages through the day from 01 to 26 March at $2-5 \mathrm{~m}$.

uncertain after the flux event, in the following we focus on the period prior to the culmination (during the buildup of the bloom) when there is no apparent alternative target to the sinking krill pellets.

The total backscatter from sinking pellets increased in parallel with the spring bloom all the way to its culmination (Fig. 11A), whereas the krill biomass was fairly stable (Fig. 11B). The Chl a values reached levels much higher than $M$. norvegica normally encounters in more oceanic habitats. The continuous increase in pellet production suggests that the krill did not reach feeding saturation, even at very high algal concentrations. Such continuous increase in feeding would be in accordance with studies of Antarctic krill (Euphausia superba) that concluded that, with high food availability, krill fed "superfluously," digesting their food incompletely and producing high numbers of loosely packed FPs (Atkinson et al. 2012). On the other hand, krill exposed to low phytoplankton concentrations processed the food in a different way, producing more densely packed pellets that had a faster sinking speed. We therefore checked for any changes in sinking speed related to progression of the bloom, yet found no relation (Fig. 12; Table 3).

Sinking speeds and vertical flux-The average sinking speeds in this study ( $423 \mathrm{~m} \mathrm{~d}^{-1}$ to $\left.804 \mathrm{~m} \mathrm{~d}^{-1}\right)$ are in agreement with earlier measurements for krill pellets, yet reported ranges are large. In a review, Turner (2002) referred to krill FP sinking speeds of $16-862 \mathrm{~m} \mathrm{~d}^{-1}$. Fowler and Small (1972) found that M. norvegica on natural food had sinking speeds at the upper end of this range. Youngbluth et al. (1989) found that 3-10 $\mathrm{mm}$ long pellets of $M$. norvegica sank at an average speed of $204 \mathrm{~m} \mathrm{~d}^{-1}$. Later studies have reported speeds $27-1218 \mathrm{~m} \mathrm{~d}^{-1}$, with a mean of $309 \mathrm{~m} \mathrm{~d}^{-1}$ (Atkinson et al. 2012) for Antarctic krill with the same average FP widths as in our samples. There are several studies showing that krill produce larger and faster-sinking FPs when produced on diatoms (likely for the spring bloom diet in our study; Kristiansen et al. 2001) compared to non-diatom phytoplankton (Cadée et al. 1992; González 1992; Atkinson et al. 2012). M. norvegica is also a large krill species, and larger species tend to make larger and faster sinking FPs (Atkinson et al. 2012). 
We found that sinking speed had a close relation to the TS (Fig. 13), which is a proxy for size. This concurs with other studies concluding that sinking speeds are dependent on size of FPs (Small et al. 1979; Komar et al. 1981; Atkinson et al. 2012). Small et al. (1979) found that FP volume explained $92 \%$ of the sinking speed variation in copepods and krill, and some of these krill were $M$. norvegica. Later studies have also included the densities of the FPs (which varies with diet) to explain the variation. Atkinson et al. (2012) found that length, width, and density of the FPs explained $76 \%$ of the variation in sinking speed in Antarctic krill. TS and sinking speed increased with range, which indicates that smaller FPs are underrepresented at longer ranges. This makes shorter ranges more suitable for estimates of sinking speed for an average of all sizes of FPs.

This is the first study to use echo sounders for addressing sedimentation of krill FPs, and it has shown that echo sounders can provide direct observation of the sedimentation process. This approach provides both short-term (i.e., diel) and long-term (i.e., seasonal) temporal resolution of pellet production; it also provides information on sinking rates and can reveal to what extent pellets are produced at depth or exported from upper waters, which may be an issue with the use of sediment traps. We have not quantified pellet flux, which may be possible if reliable TS-to-size relationships of pellets are obtained.

In this particular study, we benefited from hypoxic waters in a low advective environment, i.e., the weak targets were not swamped by strong targets and individual pellets remained in the acoustic beam for prolonged periods of time. Use of short ranges and higher acoustic frequencies will increase the ability to detect smaller targets. Therefore, acoustic assessment of pellet flux should be possible also in other habitats and for other species. Pellets of the Antarctic krill are larger (up to $3.4 \mathrm{~cm}$; Atkinson et al. 2012) and are thus stronger acoustic targets. It might further be possible to filter out strong echoes during acoustic post-processing, so that weak targets could also be detected in settings with more co-occurring targets than in the hypoxic waters of Bunnefjorden. In conclusion, the use of echo sounders, preferentially in combination with, e.g., sediment traps, holds promise for new ways of assessing vertical pellet flux.

\section{Acknowledgment}

We would like to thank NIVA for providing us with continuous data on fluorescence from their Ferrybox system.

\section{References}

Alldredge, A. L., C. C. Gotschalk, and S. Macintyre. 1987. Evidence for sustained residence of macrocrustacean fecal pellets in surface waters off southern California. Deep-Sea Res. 34: 1641-1652, doi:10.1016/0198-0149(87)90113-0

Atkinson, A., K. Schmidt, S. Fielding, S. Kawaguchi, and P. A. GeIsSLER. 2012. Variable food absorption by Antarctic krill: Relationships between diet, egestion rate and the composition and sinking rates of their fecal pellets. Deep-Sea Res. II 59: 147-158, doi:10.1016/j.dsr2.2011.06.008

Balk, H., And T. Lindem. 2012. Sonar 4 and Sonar 5-Pro Post processing systems. Operator manual 6.0.1. Lindem Data Acquisition [accessed 2012 December 1]. Available from http://folk.uio.no/hbalk/sonar4_5/index.htm
Beyer, F. 1968. Zooplankton, zoobenthos, and bottom sediments as related to pollution and water exchange in the Oslofjord. Helgol. Mar. Res. 17: 496-509.

Billett, D. S. M., R. S. Lampitt, A. L. Rice, and R. F. C. Mantoura. 1983. Seasonal sedimentation of phytoplankton to the deep-sea benthos. Nature 302: 520-522, doi:10.1038/ $302520 \mathrm{a} 0$

Bodungen, B. V., K. V. Bröckel, V. Smetacek, and B. Zeitzschel. 1981. Growth and sedimentation of the phytoplankton spring bloom in the Bornholm Sea (Baltic Sea). Kiel. Meeresforsh. Sonderh. 5: 49-60.

Briggs, N., M. J. Perry, I. Cetinić, C. Lee, E. D’Asaro, A. M. Gray, AND E. ReHM. 2011. High-resolution observations of aggregate flux during a sub-polar North Atlantic spring bloom. Deep-Sea Res. I 58: 1031-1039, doi:10.1016/j.dsr. 2011.07.007

Cadée, G. C., H. González, and S. B. Schnackschiel. 1992. Krill diet affects fecal string settling. Polar Biol. 12: 75-80.

Demer, D. A. 2004. An estimate of error for the CCAMLR 2000 survey estimate of krill biomass. Deep-Sea Res. II 51: 1237-1251.

EngÅs, A., R. Skeide, and C. W. West. 1997. The "MultiSampler": A system for remotely opening and closing multiple codends on a sampling trawl. Fish. Res. 29: 295-298, doi:10.1016/S0165-7836(96)00545-0

Foote, K. G., H. P. Knudsen, G. Vestnes, D. N. MacLennan, AND E. J. Simmonds. 1987. Calibration of acoustic instruments for fish density estimation: A practical guide. Coop. Res. Rep. Cons. Int. Explor. Mer 144: 1-69.

Fowler, S. W., and L. F. Small. 1972. Sinking rates of euphausiid fecal pellets. Limnol. Oceanogr. 17: 293-296, doi:10.4319/lo.1972.17.2.0293

GonZÁLEZ, H. E. 1992. The distribution and abundance of krill faecal material and oval pellets in the Scotia and Weddell Seas (Antarctica) and their role in particle flux. Polar Biol. 12: 81-91, doi:10.1007/BF00239968

Honjo, S., S. J. Manganini, R. A. Krishfield, and R. Francois. 2008. Particulate organic carbon fluxes to the ocean interior and factors controlling the biological pump: A synthesis of global sediment trap programs since 1983. Prog. Oceanogr. 76: 217-285, doi:10.1016/j.pocean.2007.11.003

Horne, J. K., AND J. M. JeCh. 2005. Models, measures, and visualizations of fish backscatter, p. 374-397. In H. Medwin [ed.], Sounds in the sea: From ocean acoustics to acoustical oceanography. Cambridge Univ. Press.

KaArtvedt, S., T. Larsen, K. Huelmseth, and M. S. R. OnsRud. 2002. Is the omnivorous krill Meganyctiphanes norvegica primarily a selectively feeding carnivore? Mar. Ecol. Prog. Ser. 228: 193-204, doi:10.3354/meps 228193

- A. Røstad, And T. A. Klevjer. 2009. Sprat Sprattus sprattus can exploit low oxygen waters for overwintering. Mar. Ecol. Prog. Ser. 390: 237-249, doi:10.3354/meps08196

Klevjer, T. A., And S. KaArtvedt. 2006. In situ target strength and behaviour of northern krill (Meganyctiphanes norvegica). ICES J. Mar. Sci. 63: 1726-1735, doi:10.1016/j.icesjms.2006. 06.013

, AND 2 2011. Krill (Meganyctiphanes norvegica) swim faster at night. Limnol. Oceanogr. 56: 765-774, doi:10.4319/lo.2011.56.3.0765

Komar, P. D., A. P. Morse, L. F. Small, and S. W. Fowler. 1981. An analysis of sinking rates of natural copepod and euphausiid fecal pellets. Limnol. Oceanogr. 26: 172-180, doi:10.4319/1o.1981.26.1.0172

Kristiansen, S., T. Farbrot, and L. J. Naustvoll. 2001. Spring bloom nutrient dynamics in the Oslofjord. Mar. Ecol. Prog. Ser. 219: 41-49, doi:10.3354/meps 219041 
LAmpitT, R. S. 1985. Evidence for the seasonal deposition of detritus to the deep-sea floor and its subsequent resuspension. Deep-Sea Res. 32: 885-897, doi:10.1016/0198-0149(85)90034-2

Martens, P. 1978. Faecal pellets. Fich. Ident. Zooplancton 162: $1-4$.

Mauchline, J., And L. R. Fisher. 1969. The biology of euphausiids. Academic Press.

Moore, H. B. 1931. The specific identification of faecal pellets. J. Mar. Biol. Ass. U.K. 17: 359-365, doi:10.1017/S0025315400050888

OnsRud, M. S. R., And S. KaARTVEdT. 1998. Diel vertical migration of the krill Meganyctiphanes norvegica in relation to physical environment, food and predators. Mar. Ecol. Prog. Ser. 171: 209-219, doi:10.3354/meps171209

Osgood, K. E., AND D. M. CHECKLEY. 1997. Seasonal variations in a deep aggregation of Calanus pacificus in the Santa Barbara Basin. Mar. Ecol. Prog. Ser. 148: 59-69, doi:10.3354/meps148059

Pasternak, A., E. Arashkevich, C. W. Riser, T. Ratkova, and P. Wassmann. 2000. Seasonal variation in zooplankton and suspended faecal pellets in the subarctic Norwegian Balsfjorden, in 1996. Sarsia 85: 439-452.

Petersen, W., F. Schroeder, and F. D. Bockelmann. 2011. FerryBox-application of continuous water quality observations along transects in the North Sea. Ocean Dyn. 61: 1541-1554, doi:10.1007/s10236-011-0445-0

Riebesell, U. 1991. Particle aggregation during a diatom bloom. II. Biological aspects. Mar. Ecol. Prog. Ser. 69: 281-291, doi: $10.3354 / \mathrm{meps} 069281$

Saba, G. K., and D. K. Steinberg. 2012. Abundance, composition, and sinking rates of fish fecal pellets in the Santa Barbara Channel. Sci. Rep. 2: 716, doi:10.1038/srep00716

Sameoto, D. D. 1980. Relationships between stomach contents and vertical migration in Meganyctiphanes norvegica, Thysanoessa raschii and $T$. inermis (Crustacea Euphausiacea). J. Plankton Res. 2: 129-143, doi:10.1093/plankt/2.2.129

Simard, Y., G. Lacroix, and L. Legendre. 1986. Diel vertical migrations and nocturnal feeding of a dense coastal krill scattering layer (Thysanoessa raschi and Meganyctiphanes norvegica) in stratified surface waters. Mar. Biol. 91: 93-105, doi:10.1007/BF00397575

Small, L. F., S. W. Fowler, AND M. Y. ÜNLÜ. 1979. Sinking rates of natural copepod fecal pellets. Mar. Biol. 51: 233-241, doi:10.1007/BF00386803
Solberg, I., T. A. Klevjer, and S. KaArtvedt. 2012. Continuous acoustic studies of overwintering sprat Sprattus sprattus reveal flexible behavior. Mar. Ecol. Prog. Ser. 464: 245-256, doi:10.3354/meps09877

Turner, J. T. 2002. Zooplankton fecal pellets, marine snow and sinking phytoplankton blooms. Aquat. Microb. Ecol. 27: 57-102, doi:10.3354/ame027057

Wassmann, P. 1997. Retention versus export food chains: Processes controlling sinking loss from marine pelagic systems. Hydrobiology 363: 29-57, doi:10.1023/A:1003113403096

Weimer, R. T., AND J. E. Ehrenberg. 1975. Analysis of thresholdinduced bias inherent in acoustic scattering cross-section estimates of individual fish. J. Fish. Res. Board Can. 32: 2547-2551, doi:10.1139/f75-299

Wexels Riser, C., M. Reigstad, and P. Wassmann. 2010. Zooplankton-mediated carbon export: A seasonal study in a northern Norwegian fjord. Mar. Biol. Res. 6: 461-471, doi:10.1080/17451000903437067

, P. Wassmann, K. Olli, A. Pasternak, and E. ArashreVICH. 2002. Seasonal variation in production, retention and export of zooplankton faecal pellets in the marginal ice zone and central Barents Sea. J. Mar. Syst. 38: 175-188, doi:10.1016/S0924-7963(02)00176-8

Yoon, W. D., S. K. Kim, AND K. N. Han. 2001. Morphology and sinking velocities of fecal pellets of copepod, molluscan, euphausiid, and salp taxa in the northeastern tropical Atlantic. Mar. Biol. 139: 923-928, doi:10.1007/s002270100630

Youngbluth, M. J., T. G. Bailey, P. J. Davoll, C. A. Jacoby, P. I. Blades-Eckelbarger, and C. A. Griswold. 1989. Fecal pellet production and diel migratory behavior by the euphausiid Meganyctiphanes norvegica effect benthic-pelagic coupling. Deep-Sea Res. 36: 1491-1501, doi:10.1016/01980149(89)90053-8
Associate editor: Thomas Kiørboe

Received: 30 January 2013 Accepted: 08 July 2013 Amended: 23 July 2013 